Article

\title{
Building Adaptive Capacity through Learning in Project-Oriented Organisations in Infrastructure Planning
}

\author{
Bert de Groot ${ }^{1,2, *}$, Wim Leendertse ${ }^{1,2}$ and Jos Arts ${ }^{1}$ \\ ${ }^{1}$ Department of Planning, Faculty of Spatial Sciences, University of Groningen, 9747 AD Groningen, The Netherlands; \\ E-Mails: e.a.j.de.groot@rug.nl (B.d.G),w.l.leendertse@rug.nl (W.L.), jos.arts@rug.nl (J.A.) \\ ${ }^{2}$ Rijkswaterstaat, Ministry of Infrastructure and Water Management, 3526 LA Utrecht, The Netherlands \\ * Corresponding author
}

Submitted: 30 September 2019 | Accepted: 22 November 2019 | Published: 6 March 2020

\begin{abstract}
Transport infrastructure networks are currently being challenged by rapidly changing contexts, such as climate change, new IT and mobility technologies, ageing infrastructure, demographic changes and growing engagement of stakeholders. These challenges call for an adaptive management approach in infrastructure planning. Apart from making the physical infrastructure more adaptive, organisational adaptive capacity is currently being discussed in both literature and practice. The literature describes learning as one of the key elements of organisational adaptive capacity. However, it remains unclear how infrastructure network agencies learn. Most of these agencies are organised in a project-oriented way. Projects can be considered as information exchange platforms of individuals that have to align their knowledge and interpretations to collectively make sense of this information to deliver a project-result. However, projects operate relatively autonomously from their parent organisation. This article aims to enhance the understanding of how projects learn from each other and how the parent organisation learns from projects and vice versa. To this end, we have conducted an in-depth case study of a typical project-oriented organisation in infrastructure planning: Rijkswaterstaat-the executive agency of the Ministry of Infrastructure and Water Management in the Netherlands. Data was collected through documents and semi-structured interviews with members of a selection of projects of Rijkswaterstaat and other members of this organisation. We used Social Network Analysis to support the analysis of the data. Subsequently, the results were confronted with literature to understand how collective learning occurs in project-oriented organisations.
\end{abstract}

\section{Keywords}

adaptive capacity; collective learning; infrastructure planning; project-oriented organisation; social network analysis

\section{Issue}

This article is part of the issue "Comparative Planning, Learning and Evolving Governance" edited by Kristof Van Assche (University of Alberta, Canada), Raoul Beunen (Open University of the Netherlands, The Netherlands) and Stefan Verweij (University of Groningen, The Netherlands).

(C) 2020 by the authors; licensee Cogitatio (Lisbon, Portugal). This article is licensed under a Creative Commons Attribution 4.0 International License (CC BY).

\section{Introduction}

Infrastructure systems are becoming increasingly complex due to their connections with the surrounding area, new developments in mobility, and the more dominant role of stakeholders. Increasing complexity causes a greater degree of unpredictability in infrastructure planning and requires that infrastructure systems dynamically adapt to changing contexts. In order to effi- ciently realise or improve infrastructure facilities, infrastructure network agencies often use projects, thereby arranging themselves as project-oriented organisations (Gemünden, Lehner, \& Kock, 2018). Projects typically operate within set conditions to deliver a predefined result. These constraints imply that it might be difficult for individual projects and project-oriented organisations as a whole to adapt to changing circumstances. In fact, complex infrastructure projects in the Netherlands are still 
struggling with delays, cost overruns, and dynamic stakeholder environments, which suggest insufficient adaptation. The accompanying undesirable societal effects require a more adaptive approach towards change and uncertainty. Although adaptation is only visible in hindsight, organisations can create the conditions for adaptation by optimising the adaptive capacity of the organisation.

Adaptive capacity is generally described in the literature as the capacity of a system to absorb disruption and reorganise so as to still retain essentially the same function, structure, identity, and feedback (see, e.g., Gunderson \& Holling, 2002). Adaptive capacity can thus be broadly understood as the ability of a system to cope with changing conditions. In infrastructure planning, adaptive capacity tends to be focussed on the physical part of infrastructure. However, Brown, Seville, and Vargo (2017) argue that it is also important for infrastructure network agencies to strengthen the adaptive capacity of the organisation itself. Enhancing adaptive capacity of organisations is perceived in literature and practice as an answer to the aforementioned increasing uncertainty and dynamics (Skrimizea, Haniotou, \& Parra, 2019).

There is a general consensus in the literature that adaptive capacity and collective learning are linked (see, e.g., Raymond \& Cleary, 2013; Yuen, Jovicich, \& Preston, 2013). However, despite various calls for empirical evidence of the effectiveness of learning processes to the adaptive capacity of an organisation, we only found limited proof. For example, van Epp and Garside (2019) argue in their article a positive link based on limited empirical analysis. In our article, we also assume a positive relationship between adaptive capacity and learning in the organisation. This is based on the theoretical argument that collective learning can be seen as a process of adaptation consisting of changes in common understanding, mutual agreement, and collective action (Phuong, Biesbroek, \& Wals, 2017). The ability to build new knowledge, relationships, and practices in response to complex environmental challenges links collective learning to adaptive capacity (Collins \& Ison, 2009; Ensor \& Harvey, 2015). Collective learning as a process comprises collecting data (monitoring), recognising patterns in these data (information) and giving meaning to this information related to new tasks and contexts (knowledge), evaluating and reflecting on the learning process and diffusing results (Raymond \& Cleary, 2013). Given the aforementioned description of adaptive capacity, collective learning can hence be considered a proxy for adaptive capacity. Literature generally assumes a positive relationship between learning and adaptive capacity. However, since learning is defined as using built-up knowledge in new contexts, path dependency may also restrict possible variation and thereby reduce the adaptive capacity of the organisation. Although collective learning partly occurs through internalising explicit knowledge by individuals, social interaction is an important aspect in making the learning process and products collective, so we also considered literature on social learning with social interaction as defining characteristic (see, e.g., Doloriert, Boulton, \& Sambrook, 2017). Both social and collective learning concern a change in understanding that goes beyond the individual (Backström, 2004; Keen, Brown, \& Dyball, 2005; Reed et al., 2010). For consistency, we will use the term collective learning in this article.

In project-oriented organisations, collective learning takes place at different levels: learning within projects (intra-project learning), learning between projects (interproject learning), and learning by the parent organisation from projects (called meta-project learning in this article). As an ongoing process, collective learning leads to a wealth of knowledge over time. Experiences, for example, the collapse of a bridge due to faster concrete deterioration than expected, influence the further development of knowledge. However, experiences in projects are fragmented across an organisation. Weichhart and Stary (2017) argue that especially collective learning across levels contributes to the adaptive capacity of an organisation. However, it remains unclear how this actually occurs, specifically in project-oriented organisations in infrastructure planning. Therefore, the aim of this article is to get a better understanding of how collective learning, as a proxy for adaptive capacity, occurs in project-oriented organisations in infrastructure planning. This leads to the following research question for this article: How does collective learning occur in projectoriented organisations in infrastructure planning?

To answer this question, we performed a literature search on collective learning and developed a framework to analyse collective learning in practice. We conducted an in-depth case study of a typical project-oriented organisation in infrastructure planning: Rijkswaterstaatthe executive agency of the Ministry of Infrastructure and Water Management in the Netherlands. Data was collected through documents and semi-structured interviews with participants of a selection of projects of Rijkswaterstaat and other members of this organisation. We used Social Network Analysis (SNA) to support the analysis of the data, particularly the flow of information between and from the selected (infrastructure) projects. Subsequently, the results were confronted with literature to understand how collective learning occurs in project-oriented organisations.

\section{Methodology}

The theoretical background of this article was based on a literature search. We searched Web of Science and Elsevier Scopus using "collective learning" or "social learning" and "interplay" and "adaptive capacity" as codes. In the results, the systematic review of Phuong et al. (2017) was considered the most relevant one, because this was the most recent and extensive review of the interplay between collective learning and adaptive capacity. We used this review to perform a backward reference search. We focussed on publications that described the interplay between adaptive capacity and 
collective learning and considered conditions that enhanced collective learning in an organisational setting. We confined our search to publications not older than 10 years since the discourse about the interplay between collective learning and adaptive capacity of organisations is relatively recent, as also indicated by Phuong et al. (2017). A total of 25 studies were finally retained for our study.

We chose Rijkswaterstaat for an in-depth case study. Rijkswaterstaat is the executive agency of the Ministry of Infrastructure and Water Management in the Netherlands. Rijkswaterstaat uses projects for maintenance, reconstruction and renewal of infrastructure facilities and is organised as a project-oriented organisation (Rijkswaterstaat, 2018). For our study, we looked for similar projects containing an above-average degree of uncertainty and change. We used the following selection criteria: DBFM (Design-Build-Finance-Maintain), as this is a relatively new and complicated type of contract; a challenging environment, i.e., many stakeholders; projects in the realisation phase, because of the large amount of different activities and time pressure; and highways as a specific type of infrastructure, because highway projects are often contested and experience pressure from the environment. This resulted in six projects clustered in two metropolitan regions: Amsterdam and Rotterdam. The three projects in the Amsterdam region were part of a programme. The realisation phase of the selected projects started in the period between 2010 and 2018 with an interval of one to two years, enabling us to analyse whether projects had learned from past projects. Table 1 shows information about these projects.

Collective learning takes place by and between actors (Zappa \& Robins, 2016) who are part of or create social networks (Bener, Caglayan, Henry, \& Pralat, 2016; Siciliano, 2017). Data and information flow through these networks and are given meaning by the actors depending on the task or context at hand (Barasa, Mbau, \& Gilson, 2018; Lee, Vargo, \& Seville, 2013). To gather data about these flows of data and information and about the networks of relationships, in-depth semi-structured interviews (19) with members from Rijkswaterstaat were conducted between February and September 2019 and documents, such as the project management plans and project evaluations, were examined. Transcripts of the interviews were analysed based on codes from the framework using ATLAS.ti 8.4. To be able to derive the social networks from the interview transcripts, we used SNA. Scott $(2017$, p. 2) states that SNA "comprises a broad approach to sociological analysis and a set of methodological techniques that aim to describe and explore patterns apparent in the social relationships that individuals and groups form with each other." A social network consists of nodes, representing actors such as (groups of) individuals, departments, projects, and ties (Robins, 2015), representing the flow of information or other resources, either material or nonmaterial (Wasserman \& Faust, 1994). As it is impossible to determine beforehand who interacts with whom and to prevent us from excluding possible relevant actors, we used snowball sam-

Table 1. Information about the projects selected.

\begin{tabular}{|c|c|c|}
\hline Region & Project & Characteristics \\
\hline \multirow[t]{3}{*}{ Amsterdam } & A1/A6 Diemen-Almere Havendreef & $\begin{array}{l}\text { - Realisation 2013-2018 } \\
\text { - } 23 \mathrm{~km} \text { highway expansion } \\
\text { - } 60 \text { new constructions (e.g., bridges, viaducts, and the widest } \\
\text { aqueduct of Europe) }\end{array}$ \\
\hline & A9 Holendrecht-Diemen & $\begin{array}{l}\text { - Realisation } 2014-2020 \\
\text { - } 7 \mathrm{~km} \text { highway expansion } \\
\text { - } 3 \mathrm{~km} \text { new tunnel with } 5 \text { tubes }\end{array}$ \\
\hline & A6 Almere & $\begin{array}{l}\text { - Realisation 2016-2020 } \\
\text { - } 13 \text { km highway expansion } \\
\text { - First energy neutral highway in the Netherlands }\end{array}$ \\
\hline \multirow[t]{3}{*}{ Rotterdam } & A15 Maasvlakte-Vaanplein & $\begin{array}{l}\text { - Realisation 2010-2015 } \\
\text { - } 37 \mathrm{~km} \text { highway expansion } \\
\text { - (Re)construction of approx. } 50 \text { constructions (e.g., one of the } \\
\text { biggest vertical-lift bridges in Europe) }\end{array}$ \\
\hline & A24 Blankenburgverbinding & $\begin{array}{l}\text { - Realisation 2017-2024 } \\
\text { - New highway with connections to the A15 and A20 } \\
\text { - Various new constructions (e.g., } 2 \text { tunnels) and deepened parts }\end{array}$ \\
\hline & A16 Rotterdam & $\begin{array}{l}\text { - Realisation 2018-2024 } \\
\text { - } 11 \text { km new highway with connections to the A13 and A16 } \\
\text { - Various new constructions (e.g., a tunnel) and adjustments of } \\
\text { connecting highways }\end{array}$ \\
\hline
\end{tabular}


pling (Robins, 2015). The approach started with interviewing the project manager and the stakeholder manager of each selected project because they are supposed to have an overview of most of the relationships within a project and between a project and its environment. These 12 interviews were conducted between February and April 2019. The other seven interviews were subsequently conducted between June and September 2019 with members of other projects and departments of the parent organisation that were indicated as relevant interviewees by the first group of interviewees. By asking all the interviewees with whom they link up and which information they shared, we identified their networks of relationships. As interviewees indicated relationships between projects, departments, and other organisational entities, the network started to unfold. We considered the interviewees' relationships with other individuals as relationships between the organisational entities that they represent, enabling us to get a clear view of flows of data and information between organisational entities. The network that was created enabled us to analyse how inter-and meta-project learning occur in practice.

\section{A Framework for Collective Learning}

To structure our analysis, the framework of collective learning by Gerlak and Heikkila (2011) was considered the most relevant one because it provided a concrete and comprehensive framework of collective learning, whereas other publications merely dealt with parts of collective learning or referred to this framework. We enriched this framework with findings from studied literature to an adapted framework for our analysis. The basic framework contains structure, social dynamics, and technology and functional domain as the main characteristics or conditions that shape collective learning. Collective learning itself comprises both the learning process and learning products. The collective learning process "can be understood as a set of actions that allow new information or knowledge to be acquired, processed, shared, and transferred across individuals within a group" according to Gerlak and Heikkila (2011, p. 621). As such, the adaptive capacity of the organisation can be understood as the combination of conditions, learning process, and learning products, such as new shared ideas or strategies, and policy or institutional changes as the outcome of the learning process. Although collective learning might be influenced by exogenous factors, this study only considers the characteristics of the collective setting and the learning processes themselves.

Structure, in the framework, refers to "the design or structure of institutional arrangements," according to Gerlak and Heikkila (2011, p. 623), and is defined as "organisation and coordination of the functions, tasks, and responsibilities of actors in a group" (Heikkila \& Gerlak, 2013 , p. 501). The structure of an organisation can support or inhibit communication. Project-oriented organisations consist of projects and a parent organisation, which results in some degree of fragmentation and multilevel institutional design. The institutional design influences learning processes (Medema, Wals, \& Adamowski, 2014) and thus the adaptive capacity of the organisation (Emerson \& Gerlak, 2014). Multi-level integration reduces barriers for collective learning and supports knowledge synthesis across vertical and horizontal scales (Armitage, Marschke, \& Plummer, 2008; de Kraker, 2017; Pahl-Wostl, 2009; Reed et al., 2010). According to Eakin, Eriksen, Eikeland, and $\varnothing$ yen (2011) this can be achieved through the interplay between policy entrepreneurs, for example, in informal networks linking multiple levels of an organisation (see also Pahl-Wostl, 2009).

Heikkila and Gerlak (2013, p. 501) define social dynamics as "interrelationships and communication patterns among actors in a collective setting." Trust and an open atmosphere are considered important factors because a safe, informal, and democratic environment can support collective learning (de Kraker, 2017; Ensor \& Harvey, 2015; Gerlak \& Heikkila, 2011; Medema et al., 2014; Yuen et al., 2013). Whereas Gerlak and Heikkila (2011) used the term leaders for the influence and power of individuals on learning processes, we use the term leadership (in line with Medema et al., 2014) to underline that learning processes are fostered by a clear vision about collective learning regardless of an individual's influence or power in an organisation. Collective learning emerges from human interaction through social ties (Armitage, Berkes, Dale, Kocho-Schellenberg, \& Patton, 2011; Boyd, Ensor, Broto, \& Juhola, 2014; de Kraker, 2017; Gerlak \& Heikkila, 2011; Hurlbert \& Diaz, 2013; Phuong et al., 2017; Yuen et al., 2013). We added diversity of actors to the framework because this "can improve the quality of social networks and can trigger social learning" (Phuong et al., 2017, p. 5) or collective learning through access to external knowledge and multiple perspectives (Gerlak \& Heikkila, 2011). This diversity implies that capabilities of individuals, such as experience and the ability to share knowledge, are also relevant for collective learning (Chaffin, Garmestani, Gosnell, \& Craig, 2016; Eakin et al., 2011).

The technology and functional domain involve "technical or substantive activities (e.g., services, products, and outputs) produced by a group and the information and technological resources and tools that actors draw upon in undertaking these activities" (Heikkila \& Gerlak, 2013 , p. 501). Tools used for processing and storing information support collective learning processes in the sense that everyone can access information at any moment in time (Gerlak \& Heikkila, 2011). In other publications, this is referred to as information management (de Kraker, 2017; Medema et al., 2014). However, the limitation of these tools is that they can only process and store data, information and explicit knowledge, while collective learning also involves tacit knowledge which is transferred through social interaction. Regarding this, literature mentions rules for dialogue (Ensor \& Harvey, 2015; Medema et al., 2014) and learning platforms as tools 
to facilitate collective learning (Armitage et al., 2008; Berkes, 2009; Yuen et al., 2013) across levels, projects, areas of expertise, and between projects and the parent organisation. Learning platforms serve a purpose similar to learning integration projects (Ensor \& Harvey, 2015; Raymond \& Cleary, 2013) and bridging (de Kraker, 2017; Ensor \& Harvey, 2015; Medema et al., 2014), namely establishing collective learning across organisational barriers. Lastly, Ensor and Harvey (2015) mention the necessity of scope for change to try out new technologies or substantive activities from collective learning to occur as means to adapt. Table 2 summarises the conditions that we found from our literature search.

Combining the conditions mentioned in Table 2 and the original framework of Gerlak and Heikkila (2011) results in an adapted framework of collective learning as shown in Figure 1 . The terms from the original framework are shown in italics.

\section{Analysing Collective Learning in Project-Oriented Organisations}

This section presents the findings of this study as derived from the interviews and supported by the SNA performed, following the framework of collective learning. Figure 2 visualises the interactions mentioned during the interviews. The nodes represent the selected projects (navy blue nodes with capital letter A to F), other projects mentioned by interviewees (lavender nodes with small letters), departments (light blue nodes with capital D and number), learning platforms (yellow nodes with capital $O$ and number), and relevant entities external to Rijkswaterstaat (green nodes with capital E and number). The size of the nodes represents the degree centrality, i.e., the popularity of a node (Robins, 2015).

\subsection{Structure}

Rijkswaterstaat consists of many departments and projects, each with their own goals. Often mentioned by interviewees was the temporary character of projects. Interviewees experienced limited time for reflection and sharing of experiences due to the strict planning schedules of projects. Moreover, the parent organisation's goals change over time, but projects are held to their assignments, sometimes resulting in conflicting interests. A project director stated: "Projects will always wonder whether changes are relevant for them or not because they only exist a couple of years." Interviewees also stated that projects can more easily adapt to change, but are hindered by the parent organisation due to "standardised process frames that can't keep up with the speed of changes in the environment or a lack of capacity to support such change" as a stakeholder manager stated.

Table 2. Conditions for collective learning regarding the adaptive capacity of organisations.

\begin{tabular}{|c|c|c|}
\hline Category & Condition & Reference \\
\hline \multirow[t]{3}{*}{ Structure } & Institutional design & $\begin{array}{l}\text { Emerson and Gerlak (2014); Medema et al. (2014); } \\
\text { Phuong et al. (2017) }\end{array}$ \\
\hline & Multi-level integration & $\begin{array}{l}\text { Armitage et al. (2008); de Kraker (2017); Gerlak and Heikkila (2011); } \\
\text { Pahl-Wostl (2009); Reed et al. (2010); Weichhart and Stary (2017) }\end{array}$ \\
\hline & Informal network & $\begin{array}{l}\text { Barasa et al. (2018); Bener et al. (2016); Eakin et al. (2011); } \\
\text { Lee et al. (2013); Pahl-Wostl (2009); Siciliano (2017) }\end{array}$ \\
\hline \multirow[t]{5}{*}{ Social Dynamics } & $\begin{array}{l}\text { Trust and an open } \\
\text { atmosphere }\end{array}$ & $\begin{array}{l}\text { de Kraker (2017); Ensor and Harvey (2015); Gerlak and } \\
\text { Heikkila (2011); Medema et al. (2014); Yuen et al. (2013) }\end{array}$ \\
\hline & Leadership & Gerlak and Heikkila (2011); Medema et al. (2014) \\
\hline & Interaction & $\begin{array}{l}\text { Armitage et al. (2011); Boyd et al. (2014); Collins and Ison (2009); } \\
\text { de Kraker (2017); Doloriert et al. (2017); Gerlak and Heikkila (2011); } \\
\text { Hurlbert and Diaz (2013); Phuong et al. (2017); Yuen et al. (2013); } \\
\text { Zappa and Robins (2016) }\end{array}$ \\
\hline & Diversity & Phuong et al. (2017) \\
\hline & Capabilities of individuals & Chaffin et al. (2016); Eakin et al. (2011) \\
\hline \multirow{4}{*}{$\begin{array}{l}\text { Technology and } \\
\text { Functional Domain }\end{array}$} & Information management & de Kraker (2017); Gerlak and Heikkila (2011); Medema et al. (2014) \\
\hline & Rules for dialogue & Ensor and Harvey (2015); Medema et al. (2014) \\
\hline & Learning platforms & $\begin{array}{l}\text { Armitage et al. (2008); Berkes (2009); de Kraker (2017); } \\
\text { Ensor and Harvey (2015); Gerlak and Heikkila (2011); } \\
\text { Medema et al. (2014); Raymond and Cleary (2013); } \\
\text { Yuen et al. (2013) }\end{array}$ \\
\hline & Scope for change & Ensor and Harvey (2015) \\
\hline
\end{tabular}




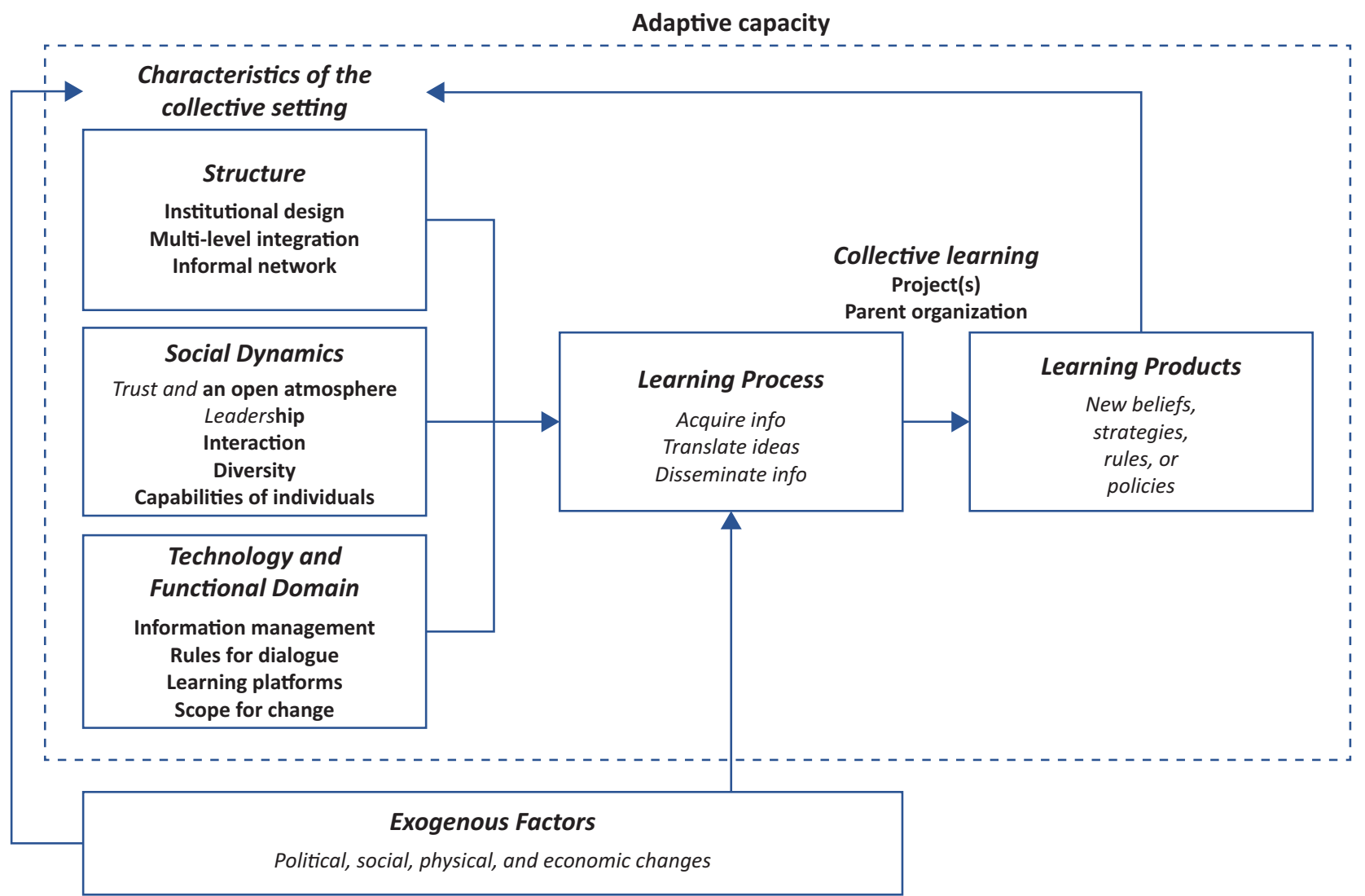

Figure 1. Framework of collective learning (adapted from Gerlak \& Heikkila, 2011).

All the projects studied are coordinated by a project management team representing various specialisms, an integrated project management team. According to the interviewees, the focus on these specialisms caused most of the interaction between project members to take place within the boundaries of these specialisms. However, the managers regularly discussed issues that could not be solved within their specialism and forced them out of their boundaries. Interviewees viewed their informal networks that were particularly important for discussing issues, although they predominantly used it for problemsolving and thus reactive learning. Proactive learning, without the urgency of a problem to be solved, hardly occurs according to the interviewees, mostly due to the pressure of deadlines and daily operations in projects.

This problem orientation in projects causes projects to become "islands drifting away from the parent organisation" as a portfolio manager described it. Especially large projects or programmes with their own, sometimes specially developed rules and processes are susceptible to a sceptical attitude by the parent organisation or other projects. "Large projects are sometimes viewed with a mixture of jealousy and envy, particularly because things are invented in these projects," said the Programme director. A portfolio manager explained that this is because "you are basically being pampered and secluded in a programme." Figure 3 shows that departments of the parent organisation are considered more on the periphery of the network studied.
To overcome structural problems, two measures were mentioned by the interviewees. First, projects can be bundled into multi-project programmes. For example, a stakeholder manager who worked in a programme stated: "Working in a programme offers much comfort, and procedures are organised very well because you do it together and there is an entire organisation behind it." Projects $A, B$, and $C$ in Figure 3 were realised in the same region (Amsterdam), shared many stakeholders, had to deal with similar issues, and were embedded in one overall programme. As shown in Figures 2 and 3, their nodes are closer to each other than other projects studied. Interviewees particularly mentioned frequent information transfer and switching of project members between projects within the programme. Most of these aspects also hold true for projects $E$ and $F$, which were realised in another region (Rotterdam). However, these projects were not embedded in a programme structure, explaining the greater distance between the nodes. Project $D$ was realised a few years earlier, also in the Rotterdam region.

A second measure mentioned by interviewees was that employees of the parent organisation can be positioned in multiple projects to secure that organisational and project goals are aligned and to enhance interand meta-project learning. A stakeholder manager mentioned such a co-worker: "We have an asset manager in our team. She works at the regional department and makes connections with other projects in the region where she takes her learning experiences." 


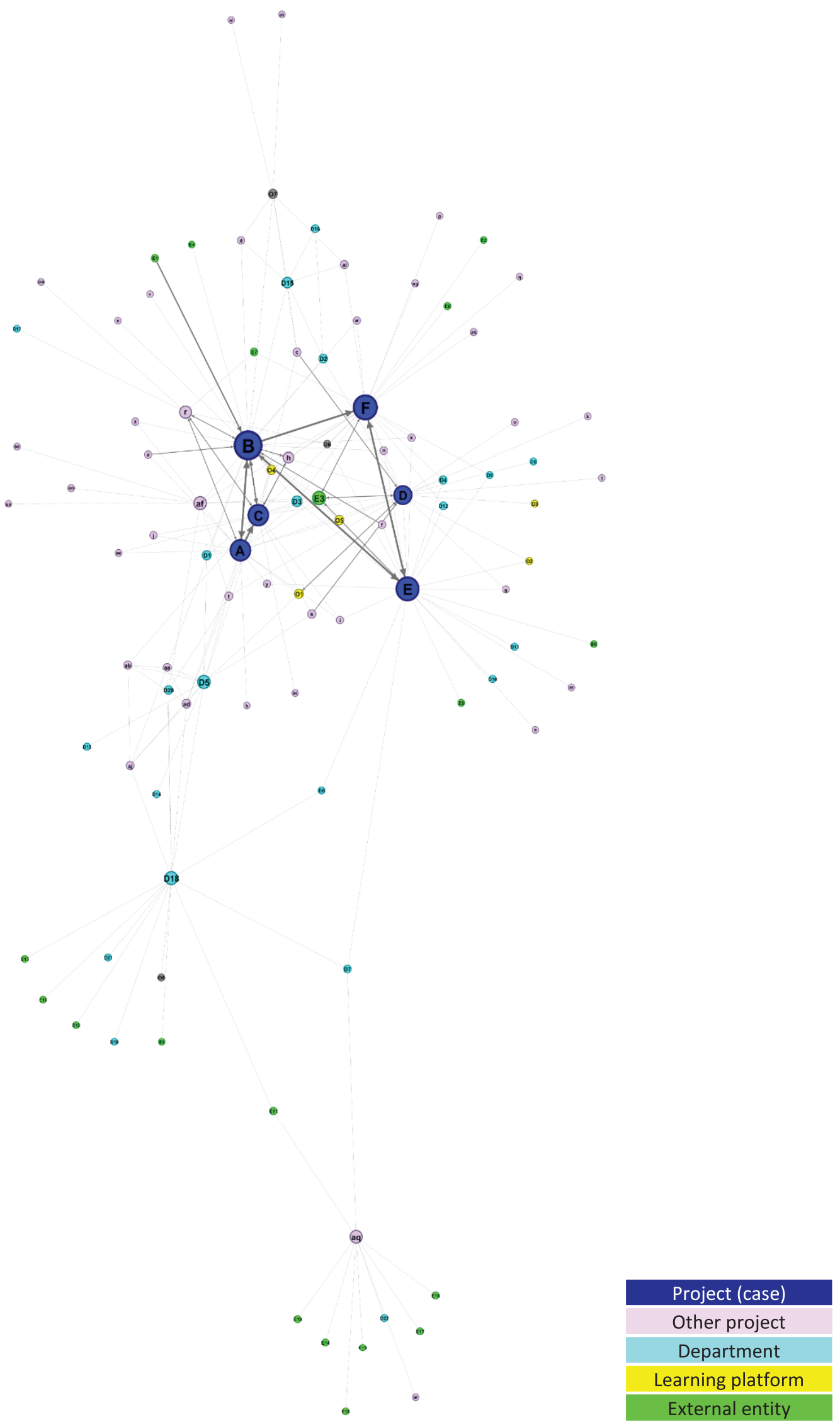

Figure 2. Network visualisation of interactions in the case studied. 


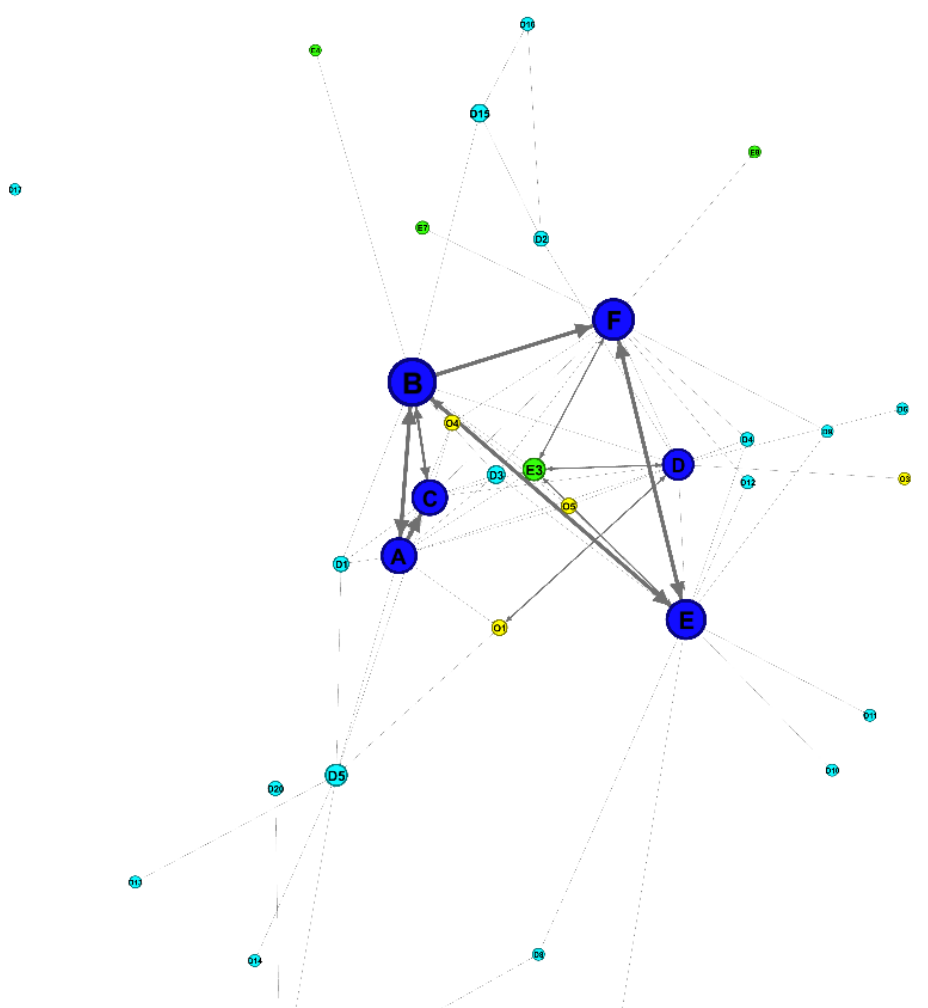

Figure 3. Selection of nodes. Notes: Projects (blue nodes), departments (bright blue nodes), internal learning platforms (yellow nodes), and external learning platforms (green nodes).

\subsection{Social Dynamics}

Regularly mentioned was the issue of learning from mistakes. A condemning attitude of the clients in the parent organisation was seen by interviewees as a barrier to discuss mistakes openly, stressing the need for a safe environment and trust for collective learning. "You actually only really do this once you trust each other very much," a project manager stated. However, it takes time and interaction to build trust. Within projects, people regularly meet and build relationships. Between projects, relationships are less intensive and mostly concentrated in peer groups that speak the same language and work in a similar environment. Interviewees often used their social ties outside regular structures when they had to solve a problem or needed peer consultancy. An interviewee stressed that "a different view might open your eyes to other solutions." Trust relationships between projects and the parent organisation prove to be much harder to create because of less intensive interaction and the slightly different worlds of working. Moreover, interviewees mentioned that projects are reluctant to share information outside their projects to avoid interference, especially when it concerns new approaches. However, a portfolio manager stated that "nobody has ever been fired because of making a mistake."

Having knowledge is considered necessary for good project results. However, knowledge generally resides with a few specialists. Because of this scarcity, people are replaced with other projects or assigned to several projects. A stakeholder manager explained:

When the problem is big enough, facilities are created that allow me to get involved in the three biggest projects in my region, but there is a lot to gain when it comes to how you actually transfer knowledge to people who are the future of our organisation.

Furthermore, people come and go. This influences the building of trust relationships. Moreover, external consultants or temporarily hired employees take their knowledge and learned lessons with them, inhibiting dissemination of information within the organisation.

\subsection{Technology and Functional Domain}

Interviewees viewed information management to be little useful for collective learning because projects always have unique characteristics. It takes much effort to externalise knowledge and store it in systems. An interviewed project manager stated that "writing evaluation reports to capture knowledge is horrible" and another project manager added that "my experience in my team is that knowledge is harder to transfer from books than from people." Some interviewees did find the process of externalising knowledge useful when it focuses on the dialogue needed to externalise. "Reflecting, discussing, and writing down experiences is a learning pro- 
cess in itself, resulting in new ideas," as a project manager stated.

Apart from a general attitude of curiosity-"only curious people learn," a portfolio manager statedinterviewees did not mention rules for dialogue. Both internal and external learning platforms were regularly mentioned as useful tools to support interaction between projects, disciplines, and across an organisation. However, interviewees predominantly engaged in learning platforms based on task specificity, e.g., regarding a specific job position, specific field of expertise, or specific types of projects. Strikingly, the most important learning platform-node E3-is an external learning platform called Neerlands Diep. Members from various projects and various governmental project-oriented organisations share experiences through this academy for public construction and infrastructure projects. Interviewees from all projects studied mentioned this learning platform and its importance for intra- and inter-project learning. The size of this node shows that this learning platform has the highest degree centrality of all learning platforms in this network, which supports the interviewees' perceived importance of this external learning platform.

When it comes to scope for change, interviewees within projects generally did not experience much space. A stakeholder manager stated that "you are judged on colouring within the lines." Interviewees within programme boards and the parent organisation stressed the importance of scope for change. However, a programme director stated that "there should always be a balance between giving space to individual project managers to do things their way, but at the same time not at the expense of the programme."

\subsection{Learning Process and Products}

SNA enables us to establish relationships in a network visible alongside the intensity of and changes in these relationships over time. Interviewees indicated which rela- tionships were present during each stage of the realisation phase of projects. We used this data to visualise relationships over time. The learning processes and resulting products regarding intra-, inter-, and meta-project learning will be described for one project from this research as an example, in this case, project $D$ and its neighbouring nodes as shown in Figure 4 (left). The realisation phase started by preparing a (DBFM-)contract and finding a contractor. Interviewees indicated that much information was acquired from multiple sources (blue lines) mainly through documents, such as evaluation reports, contracts or plans from other projects that could be used as an example-nodes $\mathrm{g}, \mathrm{k}$, and $\mathrm{I}$-and individuals bringing their knowledge and experience from past projectsnodes $c, f$, and $s$. The thicker lines represent the richness of both the information from documents and the project members' knowledge. Once a contractor started, project $D$ primarily focussed internally. At the end of the realisation phase, the project started to open up again. Information was then disseminated to other projectsnodes C, E and F-and an external learning platformnode E3 (red lines). According to the interviewees, the external learning platform facilitated the evaluation of the realisation phase, resulting in new ideas for subsequent projects and an evaluation report as learning products.

Although collective learning seems to take place quite intensively at the beginning and the end of the realisation phase, it also takes place during the rest of the realisation phase, as illustrated in Figure 4 (right). The black lines represent inter-project learning in case of an encountered problem. Nodes A, B, and t represent projects that started later than project $D$. The figure shows that projects also acquire information from parallel projects. A project manager stated: "because these projects belong to a later series, the least you can do is see how they dealt with an issue." The pink line between nodes $D$ and $u$ represents interaction about a geographical interface with another project during a short period of time. A project manager explained that "there is inten-
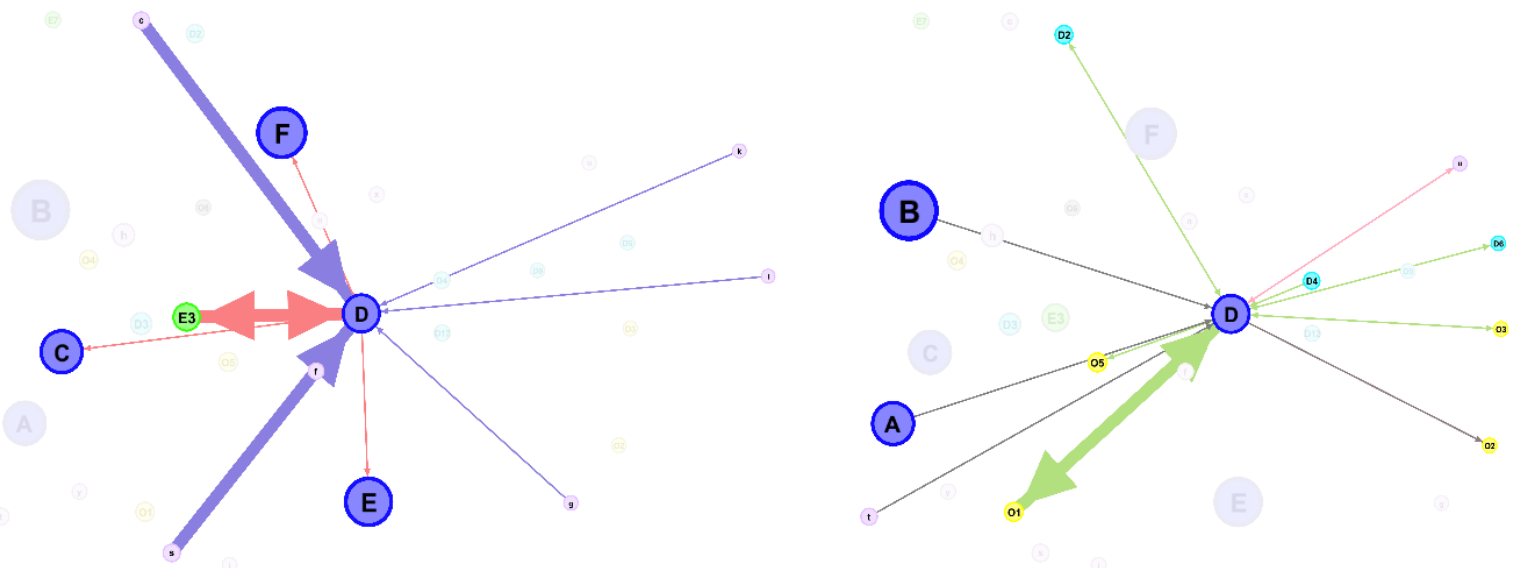

Figure 4. From left to right: Collective learning at the beginning (blue lines) and at the end (red lines) of the realisation phase; collective learning in case of an encountered problem (black line), in case of an interface (pink line), and regularly organised meetings (green lines). 
sive interaction during a couple of months and once you feel the interface is controlled, then everyone goes their own way."

Regarding meta-project learning, Figure 4 (right) shows green lines representing regularly organised meetings. There is a formal relationship with departments D2, D4, and D6 of the parent organisation. In contrast to D2 and D6, D4 represents the internal project client, which explains the greater distance of project $D$ from D2 and $D 6$. The other green lines, connecting $D$ with the yellow nodes 01, 03, and 05, represent regular informal meetings in learning platforms. Nodes $\mathrm{O} 3$ and $\mathrm{O} 5$ represent learning platforms based on specialisms, communities of practice. Professionals meet each other monthly to discuss issues in their field. The relationship between $D$ and 01 was the most intensive as this concerned a community of practice about DBFM projects, a new type of contract. The black line from project $D$ to node $\mathrm{O} 2$ represents the exchange of experiences with the DBFM contract, especially regarding encountered problems.

\section{Discussion of Collective Learning in Project-Oriented Organisations}

All the projects studied to use a formal information management system. However, this system is hardly used by projects. In externalising knowledge, some of the richness of the knowledge is lost. Moreover, explicit, general knowledge quickly becomes less useful due to the context-specific nature of projects. Therefore, learning from information exchange often occurs via the informal network. Interviewees stress that the value of a formal information management system is not the information itself, but the dialogue about information. They have the possibility to discuss insights and how it could fit their own situation. Next to learning from the information seeker's perspective, Dixon (1999) argues that such an information transfer process also helps to strengthen the speaker's understanding of that information. Hence, there are learning products at both ends of the relationship.

Furthermore, it appears that information exchange is primarily discipline-oriented, via the formal and, above all, the informal network of discipline leaders. Since projects are organised through a project team consisting of discipline managers, this greatly promotes a disciplined focus and 'homophilous' relationships, which means that people have relationships with people who are socially similar or physically close (Rogers, 2003). This makes sense because social similarity makes it easy for individuals to understand each other and physical proximity makes these relationships less time-consuming. Furthermore, it is easier to assess if someone is able to help you with an issue if you know that person. The research of Borgatti and Cross (2003) shows that for information exchange and, thus, learning it is important to know what another individual knows and how to access that knowledge. Although it is a challenge for project- oriented organisations to stimulate heterophilous relationships to enable a higher level of collective learning, this is an important condition for collective learning because "difference fosters collective learning" (Dixon, 1999, p. 53).

Apparent from the case studied is that the process and content of learning differs per project phase. In the preparation phase of a project, there is a strong focus on intra- and inter-project learning, building the team and the project. Despite a primarily internal focus in the realisation phase, still, inter-project learning occurs. In this phase, project members acquire information from other projects when they come across issues that they have not dealt with before. Typically, only at the end of the realisation phase, projects start to open up and become willing to disseminate their knowledge and experiences. Hence, projects do learn from each other, but above all, they are focused on the result to be delivered.

Although projects initially tend to focus internally and adopt a reactive approach towards collective learning, the studies shows that inter-project learning can be promoted by, first, sharing infrastructure interfaces (e.g., projects having a physical interface due to parts of the infrastructure network directly connecting to each other, and projects having to align project activities in order to minimise effects on infrastructure availability on a regional level), second, connections with the same stakeholders (e.g., clients, local governments, authorities, companies, and citizens) seemed to promote interproject learning, and third, similarities (e.g., the same type of contract, the same project phase, the same period in time, and a similar project environment). Furthermore, an explicit knowledge dissolution assignment from and facilitated by the parent organisation can help projects to invest in earlier collective learning activities.

This study suggests that a focus on projects creates an institutional distance between projects and their parent organisation, which hinders learning. Furthermore, a lack of trust between projects and the parent organisation is apparent. Daring to give confidence and allowing mistakes by the parent organisation to projects and daring to actually being involved in projects can strongly promote mutual trust-building and an open atmosphere (Ensor \& Harvey, 2015; Medema et al., 2014; Yuen et al., 2013). Although interviewees in the parent organisation indicated the presence of trust and an open atmosphere, interviewees in projects experienced otherwise. Building trust takes time. Where the ties are strongest, trust will build up the easiest. In particular, from projects to the parent organisation, these ties are relatively weak and so the build-up of mutual trust takes longer.

This institutional distance between projects and their parent organisation is frequently mentioned in the relevant literature as a problem for collective learning. However, literature about adaptive capacity suggests that a relatively weak tie to the parent organisation fosters adaptive capacity because of modularity (see, e.g., Orton \& Weick, 1990). Projects combine an efficient 
delivery of results to the possibility of localised adaptation to change. One could thus argue that projectoriented organisations are in themselves structured as adaptive organisations. The practice of studied cases shows that structures supportive to collective learning emerge (the project-oriented organisation adapts) without restructuring the organisation as a whole. Especially, learning platforms and programmes were mentioned by the interviewees.

Learning platforms such as communities of practice or educational platforms are present, although these platforms mostly support an exchange of general information and working methods. Moreover, these platforms are often organised in a discipline-oriented manner. Learning platforms are viewed by the interviewees in particular as good media for the exchange of information and especially for dialogue about issues and working methods. Strikingly, the most important learning platform-node E3-is an external learning platform called Neerlands Diep. Members from various projects and various governmental organisations share experiences through this academy for public construction and infrastructure projects. Platforms offer the possibility to reflect on issues from daily practice and share views of issues discussed. This is in line with Medema et al. (2014, p. 30): "Reflection as an integral part of learning and change processes reveals in more depth the ways in which both the external and internal context as well as individual attributes of those involved affect learning and change processes, actions and values." Moreover, external learning platforms offer the benefits of multiple perspectives (Dixon, 1999), not only extra-project but also extra-organisational, because of the participation of other organisations. However, the interviews reveal that the knowledge that is transferred or created through these platforms mostly remains within the projects that were engaged in these platforms.

Projects can be interrelated in multi-project programmes. The study results indicate that this offers a good opportunity for parallel and subsequent projects to learn from each other, given that the programme has a clear vision on learning and the learning process and an explicit organisation of that process. Programmes can facilitate intra- and inter-project learning. Gerlak and Heikkila (2011) argue that some evidence suggests that this may be effective because it promotes indirect interaction among various entities, which also holds true for learning platforms. However, the disadvantage of programmes, especially if they are large, is that they are sometimes seen as separate and exceptional by the parent organisation or other projects. Intraand inter-project learning is then promoted, but metaproject learning faces an extra barrier. Interviewees often refer to programmes as bridges between relatively autonomous projects and the parent organisation. In that sense, programmes can (become) a promising link for creating adaptive capacity in projectoriented organisations.

\section{Towards Adaptive Capacity}

In accordance with the literature, our study shows that it is precisely the scaling up of learning experiences from projects to the whole organisation that is lacking in project-oriented organisations. If projects do not receive a specific knowledge dissolution assignment from the parent organisation, they will focus exclusively on their own objectives. The study gives several reasons. The temporary nature of projects can conflict with the permanent nature of the parent organisation because goals diverge. Furthermore, due to this temporary nature, employees come and go in and between projects and in and out of the organisation. Moreover, knowledge resides with a few specialists. Well-considered management of human capital from a long-term organisational vision (instead of just capacity management) can enhance inter- and meta-project learning.

Furthermore, our study showed that programmes and learning platforms contribute to inter-project learning. These programmes and learning platforms have relationships with the parent organisation, but these relationships are relatively weak. Could stronger relationships between programmes or learning platforms and the parent organisation enhance meta-project learning? If so, how can we strengthen these relationships without creating a rigid organisation? We suggest further research on the role of learning platforms and programmes in enhancing meta-project learning.

Since the presented study is only a first exploration of collective learning as a process of building adaptive capacity in project-oriented organisations, we strongly suggest further empirical study on this subject. More specifically, we would recommend continuing the process of snowball sampling to gather more data and more perspectives, working towards a whole network. In addition to interviews, which are useful for understanding collective learning processes, surveys could be used to get more insight on learning products and complementary data to further analyse patterns within the network. SNA as a method could then also be applied more comprehensively. Furthermore, it may also be worthwhile to compare the currently studied realisation phase to other phases of a project and to study how collective learning during the transition between phases occurs. This enriches the view on collective learning processes in project-oriented organisations.

\section{Conclusion}

With this study, we aimed to reach a better understanding of how collective learning as a proxy for adaptive capacity occurs in project-oriented organisations. We started with a literature search of the conditions required for collective learning. These conditions lie in the structure and institutional design of the organisation-such as multi-level integration and the informal network-in the social dynamics within 
the organisation-such as an open atmosphere, building trust, diversity, and interaction-and in the technical functional domain - such as having an information management system, information exchange platforms, and scope for change. The (collective) learning process takes place within these conditions, which leads to learning products as building blocks for adaptive capacity.

In project-oriented organisations, collective learning takes place within and between projects, but scarcely from projects to the parent organisation. The relationship between projects and the parent organisation appears to be relatively weak compared to intra- and interproject ties. As a result, projects focus on reactively learning on behalf of their projects, delivering localised adaptation to change. However, the case studied shows interesting examples of how meta-project learning can be enhanced-such as learning platforms, employee exchange, dialogue, programmes and explicit learning assignments to projects - and thereby the building of adaptive capacity of infrastructure network agencies as a whole. We recommend further exploration of these interesting examples in practice as well as academics.

\section{Acknowledgments}

We thank Rijkswaterstaat for cooperating and providing us with data for our research.

\section{Conflict of Interests}

The authors declare no conflict of interests.

\section{References}

Armitage, D., Berkes, F., Dale, A., Kocho-Schellenberg, E., \& Patton, E. (2011). Co-management and the co-production of knowledge: Learning to adapt in Canada's Arctic. Global Environmental Change, 21, 995-1004.

Armitage, D., Marschke, M., \& Plummer, R. (2008). Adaptive co-management and the paradox of learning. Global Environmental Change, 18, 86-98.

Backström, T. (2004). Collective learning: A way over the ridge to a new organizational attractor. The Learning Organization, 11(6), 466-477.

Barasa, E., Mbau, R., \& Gilson, L. (2018). What Is resilience and how can it be nurtured? A systematic review of empirical literature on organizational resilience. International Journal of Health Policy and Management, 7(6), 491-503.

Bener, A. B., Caglayan, B., Henry, A. D., \& Pralat, P. (2016). Emperical models of social learning in a large, evolving network. PLOS ONE, 11(10), 1-20.

Berkes, F. (2009). Evolution of co-management: Role of knowledge generation, bridging organizations and social learning. Journal of Environmental Management, 90, 1692-1702.

Borgatti, S. P., \& Cross, R. (2003). A relational view of information seeking and learning in social networks. Management Science, 49(4), 432-445.

Boyd, E., Ensor, J., Broto, V. C., \& Juhola, S. (2014). Environmentalities of urban climate governance in Maputo, Mozambique. Global Environmental Change, 26, 140-151.

Brown, C., Seville, E., \& Vargo, J. (2017). Measuring the organizational resilience of critical infrastructure providers: A New Zealand case study. International Journal of Critical Infrastructure Protection, 18, 37-49.

Chaffin, B., Garmestani, A., Gosnell, H., \& Craig, R. (2016). Institutional networks and adaptive water governance in the Klamath River Basin, USA. Environmental Science \& Policy, 57, 112-121.

Collins, K., \& Ison, R. (2009). Jumping off Arnstein's ladder: Social learning as a new policy paradigm for climate change adaptation. Environmental Policy and Governance, 19, 358-373.

de Kraker, J. (2017). Social learning for resilience in socialecological systems. Current Opinion in Environmental Sustainability, 28, 100-107.

Dixon, N. (1999). The organizational learning cycle: How we can learn collectively. Abingdon: Gower Publishing.

Doloriert, C., Boulton, W., \& Sambrook, S. (2017). Facilitating collective and social learning. London: Kogan Page.

Eakin, H., Eriksen, S., Eikeland, P.-O., \& Øyen, C. (2011). Public sector reform and governance for adaptation: Implications of new public management for adaptive capacity in Mexico and Norway. Environmental Management, 47, 338-351.

Emerson, K., \& Gerlak, A. K. (2014). Adaptation in collaborative governance regimes. Environmental Management, 54(4), 768-781.

Ensor, J., \& Harvey, B. (2015). Social learning and climate change adaptation: Evidence for international development practice. WIREs Climate Change, 6, 509-522.

Gemünden, H., Lehner, P., \& Kock, A. (2018). The projectoriented organization and its contribution to innovation. International Journal of Project Management, 36(1), 147-160.

Gerlak, A. K., \& Heikkila, T. (2011). Building a theory of learning in collaboratives: Evidence from the Everglades restoration program. Journal of Public Administration Research and Theory, 21(4), 619-644.

Gunderson, L., \& Holling, C. (2002). Panarchy. understanding transformation in human and natural systems. Washington, DC: Island Press.

Heikkila, T., \& Gerlak, A. K. (2013). Building a conceptual approach to collective learning: Lessons for public policy scholars. The Policy Studies Journal, 41(3), 484-512.

Hurlbert, M. A., \& Diaz, H. (2013). Water governance in Chile and Canada: A comparison of adaptive characteristics. Ecology and Society, 18(4), 61.

Keen, M., Brown, V., \& Dyball, R. (2005). Social learning in 
environmental management: Towards a sustainable future. London: Earthscan.

Lee, A., Vargo, J., \& Seville, E. (2013). Developing a tool to measure and compare organizations' resilience. $\mathrm{Na}$ tional Hazards Review, 14(1), 29-41.

Medema, W., Wals, A., \& Adamowski, J. (2014). Multiloop social learning for sustainable land and water governance: Towards a research agenda on the potential of virtual learning platforms. NJASWageningen Journal of Life Sciences, 69, 23-38.

Orton, J. D., \& Weick, K. E. (1990). Loosely coupled systems: A reconceptualization. The Academy of Management Review, 15(2), 203-223.

Pahl-Wostl, C. (2009). A conceptual framework for analysing adaptive capacity and multi-level learning processes in resource governance regimes. Global Environmental Change, 19, 354-365.

Phuong, L. T., Biesbroek, G. R., \& Wals, A. E. (2017). The interplay between social learning and adaptive capacity in climate change adaptation: A systematic review. NJAS-Wageningen Journal of Life Sciences, 82, 1-9.

Raymond, C. M., \& Cleary, J. (2013). A tool and process that facilitate community capacity building and social learning for natural resource management. Ecology and Society, 18(1). http://dx.doi.org/10.5751/ES05238-180125

Reed, M. S., Evely, A. C., Cundill, G., Fazey, I., Glass, J., Laing, A., \& Stringer, L. C. (2010). What is social learning? Ecology and Society, 15(4), r1.

Rijkswaterstaat. (2018). About us. Rijkswaterstaat. Retrieved from https://www.rijkswaterstaat.nl/ english/about-us

Robins, G. (2015). Doing social network research:
Network-based research design for social scientists. Los Angeles, CA: SAGE Publications.

Rogers, E. M. (2003). Diffusion of innovations (5th ed.). New York, NY: Free press.

Scott, J. (2017). Social network analysis (4th ed.). London: SAGE Publications.

Siciliano, M. D. (2017). Ignoring the experts: Networks and organizational learning in the public sector. Journal of Public Administration Research and Theory, 27(1), 104-119.

Skrimizea, E., Haniotou, H., \& Parra, C. (2019). On the 'complexity turn' in planning: An adaptive rationale to navigate spaces and times of uncertainty. Planning Theory, 18(1), 122-142.

van Epp, M., \& Garside, B. (2019). Towards an evidence base on the value of social learning-oriented approaches in the context of climate change and food security. Environmental Policy and Governance, 29(2), 118-131.

Wasserman, S., \& Faust, K. (1994). Social network analysis: Methods and applications. Cambridge: Cambridge University Press.

Weichhart, G., \& Stary, C. (2017). Project-based learning for complex adaptive enterprise systems. IFAC PapersOnLine, 50(1), 12991-12996.

Yuen, E., Jovicich, S. S., \& Preston, B. L. (2013). Climate change vulnerability assessments as catalysts for social learning: Four case studies in south-eastern Australia. Mitigation and Adaptation Strategies for Global Change, 18(5), 567-590.

Zappa, P., \& Robins, G. (2016). Organizational learning across multi-level networks. Social Networks, 44, 295-306.

\section{About the Authors}

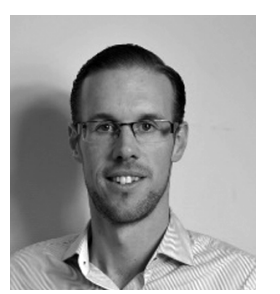

Bert de Groot is a PhD candidate at the Department of Planning, Faculty of Spatial Science, University of Groningen, the Netherlands. His research focuses on the relationship between collective learning and adaptive capacity in project-oriented organisations in infrastructure planning. Furthermore, he works as a Project management consultant in Rijkswaterstaat, part of the Ministry of Infrastructure and Water Management in the Netherlands. ORCID: https://orcid.org/0000-0001-9833-3281

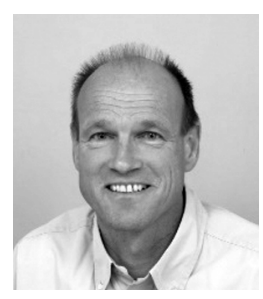

Wim Leendertse is a University Professor of Management in Infrastructure Planning at the Department of Planning, Faculty of Spatial Sciences, University of Groningen, the Netherlands, and senior advisor for Rijkswaterstaat in the field of project management, innovation management and market involvement.

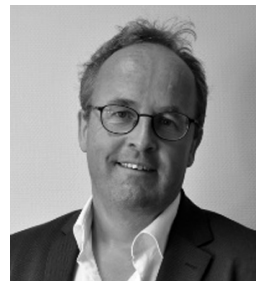

Jos Arts is Full-Professor Environment and Infrastructure Planning and Head of the Department of Spatial Planning and Environment, Faculty of Spatial Sciences, University of Groningen, the Netherlands. He has organised many international workshops and conferences and has published widely about impact assessment, evaluation and environmental, spatial and infrastructure planning. His research focuses on institutional analysis and design for integrated planning approaches for sustainable infrastructure networks. ORCID: https://orcid.org/0000-0002-6896-3992 